\title{
Posttraumatic stress disorder symptoms in children exposed to circumcision under general or local anesthesia
}

\author{
Betül Kozanhan ${ }^{1}$, Canan Kocaoğlu², Metin Gündüz ${ }^{3}$, Ömer Faruk Akça ${ }^{4}$ \\ Depatments of ${ }^{1}$ Anesthesiology and Reanimation and ${ }^{2}$ Pediatric Surgery, University of Health Sciences, Konya Training and \\ Research Hospital; ${ }^{3}$ Department of Pediatric Surgery, Selcuk University; ${ }^{4}$ Department of Child and Adolescent Psychiatry, \\ Necmettin Erbakan University, Konya, Turkey. E-mail: betulkozanhan@gmail.com \\ Received: 16th August 2017, Revised: 25th October 2017, 22nd December 2017, Accepted: 30th December \\ 2017
}

SUMMARY: Kozanhan B, Kocaoğlu C, Gündüz M, Akça ÖF. Posttraumatic stress disorder symptoms in children exposed to circumcision under general or local anesthesia. Turk J Pediatr 2018; 60: 718-725.

The aim of this study was to investigate the impact of general versus local anesthesia on the Posttraumatic Stress Disorder (PTSD) symptoms after circumcision. Of the 134 consecutive children (7-12 years of age) who underwent circumcision, 71 had general anesthesia (GA) and 63 had local anesthesia (LA). All participants completed the child depression inventory (CDI), State Anxiety (SA) and Trait Anxiety (TA) inventories, and Childhood Anxiety Sensitivity Index (CASI) before the operation as well as the Child Posttraumatic Stress Reaction Index (CPSRI) one month after the operation. The CDI, CASI and TA scores of the children were similar in both groups, while the SA scores of the LA group were higher than those in GA group $(p<0.001)$. The CPSRI scores of the GA group were higher than those of the LA group $(p=0.04)$. When the other parameters were controlled via regression analysis, only the CDI scores and being in the GA group predicted the CPSRI scores. This study suggests that children witnessing the surgical procedure of the circumcision developed no serious symptoms of PTSD. In contrast, children exposed to GA during circumcision developed more serious PTSD symptoms than children who had LA. The severity of depressive symptoms may be important in the development of PTSD symptoms after circumcision.

Key words: circumcision, general anesthesia, local anesthesia, posttraumatic stress disorder.

Male circumcision is one of the oldest and most widespread operations performed in young male patients all over the world for cultural, religious or medical reasons. ${ }^{1}$ According to the World Health Organization, an estimated $30-33 \%$ of males aged 15 and older have been circumcised across the world. ${ }^{2}$ Circumcision -an operation performed by removing the foreskin from the penis- is considered a safe, day-case, elective surgical procedure with minimal risks despite being painful. ${ }^{3}$ Therefore, it is important for clinicians to ensure that children receive appropriate anesthesia throughout the surgical procedure.

Anesthesia procedures are classified as local or general anesthesia. Topical application of local anesthetics, subcutaneous ring block of the penis and dorsal penile nerve block (DPNB) are some local anesthetic approaches. Topical application of local anesthetics provides no sufficient pain relief. ${ }^{4}$ Compared to general anesthesia (GA), local anesthesia (LA) techniques eliminate the need for an operating room, making the procedure more cost-effective and more widely available. However, because injecting anesthetics locally is often a source of pain, injections may give rise to needle anxiety and increase the pain perceived by children. Pediatric surgeons usually prefer GA to eliminate fear and anxiety in sufferers. ${ }^{5}$ 
For GA, an anesthetic drug is administered either by inhalation through a breathing mask or endotracheal tube, or by injection through an intravenous line. However, young children sedated under GA often have bad experiences, such as delirium and agitation upon becoming conscious in a foreign environment surrounded by strangers.

Several studies suggested that circumcision have some negative influences on children's psychology. 6,7 On a study with 12 children of ages 4-7, it has been concluded that children regard circumcision as an aggressive attack to their bodies ${ }^{6}$. It has also been underlined in this study that changes in perceptual body image, inadequacy and helplessness feelings are observed $^{6}$. In a large Philippines study, 70\% of boys subjected to ritual circumcision and $51 \%$ of boys subjected to medical circumcision are diagnosed Post-Traumatic Stress Disorder $(\mathrm{PTSD})^{7}$ diagnosis according to DSM-IV criteria.

PTSD is known as a source of prolonged pathological anxiety related to a previous severe trauma that constitute a threat to life or physical integrity. ${ }^{8}$ As can be seen in the DSM 4 criteria, various types of severe traumatic events can cause PTSD. However, in the most recent version of the DSM, the definition of trauma has been expanded by removing the criterion indicating that the "trauma should constitute a threat to life or physical integrity". ${ }^{9}$ Based on the knowledge that the circumcision procedure -which can be perceived as a traumatic event by the child- could cause PTSD symptoms, we designed the current study to investigate the probable traumatic effects of the procedure and to determine the possible psychological factors predicting that PTSD symptoms could be seen after the circumcision operation. We hypothesized that children circumcised under LA would be associated with more negative effects in terms of PTSD symptoms than those performed under GA because of experiencing the procedure. To the best of our knowledge, our study is the first to assess the association between the effect of the chosen anesthesia method and symptom severity of PTSD in circumcised children.

\section{Material and Methods}

The present study was conducted within a six-month period between March and August
2016. The study recruited 134 children aged 7-12 years who were scheduled for elective, day-case circumcision for religious and nontherapeutic reasons. Exclusion criteria for the study were: a) had undergone an anesthetic process within the month before circumcision; b) a history of any psychiatric disorder diagnosis such as anxiety, depression or attention deficit-hyperactivity disorder; c) have used any psychiatric medication within the last three months; d) having a cognitive impairment that would affect their ability to complete the assessments; e) having any chronic disease such as diabetes mellitus or asthma; f) had been exposed to any catastrophic events within the last year such as disasters or serious accidents.

With no randomization, the children were allocated to local or general anesthesia groups according to the parents' and the children's preferences. The patients and their parents were informed about the procedure. For participants in the LA group, the surgeon applied DPNB as the sole anesthesia using the procedure described by Serour et al. ${ }^{4}$ with minor modifications. Analgesia was evaluated by gentle pinching of the skin around the penis with mosquito artery forceps approximately 10-15 minutes after completing the block. If the evaluation showed insufficient analgesia or if the child exhibited anxiety or refused the operation at any intraoperative time, standard GA was performed, and such patients were then removed from the study. For those who chose to be circumcised under GA, the anesthesiologist administered a gas mixture of oxygen, nitrous oxide, sevoflurane $(6-8 \%)$ and fentanyl $(1-2 \mu \mathrm{g} / \mathrm{kg})$. To maintain anesthesia, $1-2 \%$ of sevoflurane and a combination of oxygen and nitrous oxide were provided. At the end of surgery, DPNB was performed as previously described for postoperative analgesia.

Two surgeons with at least 5 years of surgical experience performed the surgical procedure using the sleeve circumcision technique as described by Jordan et al. ${ }^{10}$. Before discharge, all patients were observed for 2 to 6 hours. During this postoperative period, professionals evaluated their hemodynamic stability and absence of pain, bleeding, nausea and vomiting. In the presence of pain (Visual Analogue Scale Score $>3$ ), $15 \mathrm{mg} / \mathrm{kg}$ of paracetamol was orally administered to achieve postoperative 
pain relief.

\section{Measures}

All participants were asked to fill in the Children's Depression Inventory (CDI), StateTrait Anxiety Inventory for children (STAI-C), and Childhood Anxiety Sensitivity Index (CASI) within the preoperative period, and the child Posttraumatic Stress Reaction Index (CPSRI), one month after the operation.

\section{Children's Depression Inventory (CDI)}

This assessment was used for evaluating depression levels in children and adolescents, aged between 6 to 17 years. The CDI was developed by Kovacs ${ }^{11}$ and consists of 27 items, each of which includes three statements (response options) that children declare according to their choices during preoperative two-week period. The children's responses are scored between 0 and 2 , and the total depression score for each child is obtained by adding all the scores. The maximum score obtained from the inventory is 54 , in which higher scores indicate a severe level of depression. For this study, we used the Turkish version of the CDI which demonstrates good reliability and validity in the assessment of depressive symptoms. ${ }^{12}$

\section{State and Trait Anxiety Inventory for Children (STAI-C)}

The inventory was developed by Spielberger ${ }^{13}$ and includes 2 subscales as State Anxiety (SA) and Trait Anxiety (TA), each is composed of 20 multiple-choice items. Each item is scored as 0,1 or 2 according to the severity of symptoms. SA is defined as the anxiety experienced at a certain time under certain conditions. On the other hand, TA defines the individual's feelings in general and reflects the individual's general predisposition to anxiety. The reliability and validity study of the scale for the Turkish population was conducted by Ozusta et al. ${ }^{14}$ in 1993.

\section{Childhood Anxiety Sensitivity Index (CASI)}

As a self-report index, the 18-item CASI was developed by Silverman et al. ${ }^{15}$ for school children aged between 6-17 years and is used to interpret the fear/catastrophic and physical sensations from anxiety and to rate on a threepoint Likert-type scale ranging from 1 (not at all) to 3 (very much). Total CASI scores range from 18 to 54 . The reliability and validity study of the Turkish version was conducted by Yilmaz et al. ${ }^{16}$ in a group of Turkish school children. In the present study, the scale demonstrated an adequate internal consistency (Cronbach's alpha of .74) and test-retest reliability $(r=.77)$.

\section{Children's Post-Traumatic Stress Disorder Reaction Index (CPRI)}

Developed by Pynoos et al. ${ }^{17}$, the CPRI is used to assess reactions to stressors after traumatic events experienced by children and adolescents. Indicating three main criteria such as reexperiencing, numbing and arousal, the CPRI is a 20-item self-reporting index including some of the DSM-IV PTSD symptoms. Each item is scored on a 5 -point scale $(0=$ none, $1=$ a little, $2=$ some, $3=$ much and $4=$ most of the time). The total score is performed, summing the scores obtained from each item. The general score is divided into five intensity rates as follows: between 0-11 (doubtful), 12-24 (mild), 25-39 (moderate), 40-59 (severe) and 60- 80 (very severe). In our study, we used the Turkish version of the CPRI, the validity and reliability of which were formed by Erden et al. ${ }^{18}$.

\section{Ethical approval}

For conducting the study, an approval was obtained from the ethical board of the local University (number: 2016/59; date: 01.03.2016). We informed all participants and their parents about the design of the study. Both oral and written informed consents were obtained from all parents and their children. All procedures in the study were performed in accordance with the standards of the ethical board, under the 1964 Helsinki Declaration and its later amendments.

\section{Statistical assessment}

We used Statistical Package for the Social Sciences (SPSS, version 17.0) [SPSS Statistics, Chicago, IL] for statistical analyses and used the $t$-test and Mann-Whitney U test to compare the variables in the LA and GA groups. We performed Pearson and Spearman correlation analyses for correlations and conducted a CATREG regression analysis to examine the variables predicting PTSD symptoms. Significance was accepted as $p<0.05$. 
Table I. Comparisons Between Children circumcised Under General and Local Anesthesia.

\begin{tabular}{lccc}
\hline & Local anesthesia & General anesthesia & $\mathrm{p}$ \\
\hline Age & $8.7 \pm 1.25$ & $8.4 \pm 1.13$ & 0.16 \\
Age of mothers & $34.9 \pm 5.72$ & $34.7 \pm 5.47$ & 0.54 \\
Age of fathers & $39.0 \pm 6.11$ & $38.7 \pm 5.85$ & 0.58 \\
Education level of mothers & $9.8 \pm 4.8$ & $7.0 \pm 3.4$ & $<0.01$ \\
(year) & $11.8 \pm 4.3$ & $9.4 \pm 4.1$ & $<0.01$ \\
Education level of fathers(year) & $2820 \pm 1639$ & $2143 \pm 1028$ & 0.02 \\
Total income (TL) & $11.7 \pm 4.7$ & $11.8 \pm 5.2$ & 0.90 \\
Depression & $36.9 \pm 9.1$ & $31.3 \pm 7.8$ & $<0.001$ \\
State anxiety & $39.7 \pm 8.1$ & $38.6 \pm 7.1$ & 0.41 \\
Trait anxiety & $30.0 \pm 6.0$ & $31.0 \pm 5.8$ & 0.34 \\
Anxiety sensitivity & $10.5 \pm 9.0$ & $13.8 \pm 9.5$ & 0.04 \\
PTSD & & &
\end{tabular}

PTSD: Post-traumatic stress disorder

\section{Results}

The groups were similar in terms of sociodemographic features except for the total income $(p=0.02)$ of the families and the education levels of fathers $(\mathrm{p}<0.01)$ and mothers $(\mathrm{p}<0.01)$. The CDI, CASI, and TA scores were similar in both groups; however, the SA scores of LA group were higher than those found in GA group. The CPRI scores of GA group were found to be higher than LA group (Table I). The CPRI scores were correlated to the CDI, TA, and SA scores in GA group. No significant correlation was found between the CPRI and other variables in LA group. However, we observed a correlation between the CPRI and CDI scores which seems close to significance $(p=0.052)$ (Tables II and III). When other variables (i.e., sociodemographical variables, CDI, SA, and TA) were controlled through regression analysis, only the group of the subjects and CDI scores predicted the CPRI scores. (Table IV).

\section{Discussion}

In our study, we investigated the effects of GA and LA procedures on the development of PTSD symptoms in children circumcised under elective conditions. According to our findings, PTSD symptoms caused by circumcision in children were at lower levels (doubtful to mild) in both GA and LA groups ${ }^{15}$. In LA group, determined PTSD levels based on the CPRI scores were doubtful $(n=40)$, mild $(n=16)$ or moderate $(n=7)$. Also, the PTSD levels of the subjects in the GA group were doubtful $(n=33)$, mild $(n=24)$, moderate $(n=9)$ or severe $(n=1)$. Based on psychoanalytic theory, male children are vulnerable to castration

Table II. Correlation Analysis of Children Exposed to Circumcision Under General Anesthesia.

\begin{tabular}{lcccccc}
\hline & 1 & 2 & 3 & 4 & 5 & 6 \\
\hline 1 PTSD & 1 & 0.15 & $0.27^{*}$ & $0.25^{*}$ & $0.35^{* *}$ & -0.70 \\
2 Anxiety sensitivity & & 1 & 0.17 & $0.24^{*}$ & $0.41^{* * *}$ & -0.47 \\
3 Depression & & & 1 & $0.31^{* *}$ & $0.29^{*}$ & 0.03 \\
4 State anxiety & & & & 1 & $0.47^{* * *}$ & -0.19 \\
5 Trait anxiety & & & & & -0.18 \\
6 Age & & & & & \\
$*$ p $<0.05$ & & & & & \\
$* * \mathrm{p}<0.01$ & & & &
\end{tabular}


Table III. Correlation Analysis of Children Exposed to Circumcision Under Local Anesthesia.

\begin{tabular}{lcccccc}
\hline & 1 & 2 & 3 & 4 & 5 & 6 \\
\hline 1 PTSD & 1 & 0.06 & 0.25 & 0.11 & 0.07 & -0.01 \\
2 Anxiety sensitivity & & 1 & $0.40^{* *}$ & 0.21 & $0.31^{*}$ & -0.01 \\
3 Depression & & & 1 & 0.01 & $0.31^{*}$ & 0.14 \\
4 State anxiety & & & & 1 & $0.43^{* *}$ & 0.06 \\
5 Trait anxiety & & & & 1 & 0.11 \\
6 Age & & & & & 1 \\
${ }^{*} \mathrm{p}<0.05$ & & & & & \\
${ }^{* *} \mathrm{p}<0.01$ & & & & & \\
${ }^{* * *} \mathrm{p}<0.001$ & & & & &
\end{tabular}

PTSD: Post-traumatic stress disorder

Table IV. Variables Predicting PTSD Symptoms in Children Exposed to Circumcision Operation.

\begin{tabular}{lllll}
\hline & SE & Beta & $\mathrm{t}$ & $p$ \\
\hline (Constant) & & & & \\
Group & 0.100 & 0.119 & 4.006 & 0.04 \\
Age & 0.098 & 0.018 & 0.034 & 0.85 \\
Age of mothers & 0.167 & -0.103 & 0.380 & 0.53 \\
Age of fathers & 0.172 & -0.046 & 0.072 & 0.78 \\
Education levels of mothers & 0.225 & 0.087 & 0.150 & 0.86 \\
Education levels of fathers & 0.201 & 0.072 & 0.129 & 0.72 \\
Total income & 0.199 & -0.129 & 0.421 & 0.73 \\
State anxiety & 0.116 & 0.145 & 1.554 & 0.21 \\
Trait anxiety & 0.120 & 0.016 & 0.017 & 0.89 \\
Depressive symptoms & 0.110 & 0.237 & 4.641 & 0.03 \\
\hline
\end{tabular}

anxiety, especially within the phallic period, -which includes 3 to 6 ages- meaning they are likely to be scared of experiencing penile injury. ${ }^{19}$ Likewise, Corduk et al. ${ }^{20}$ investigated the fear and worry about the circumcision retrospectively in children and reported that nearly half of the children felt worry and one third had feared from circumcision operation. However, our findings were inconsistent with those obtained in previous studies. The fact that our participants were children over the phallic period may account for such an inconsistency. Supporting this assumption, Corduk et al. ${ }^{20}$ reported that worry and fear levels of children over 7 years of age were lower than those under age 7 . In addition, cultural factors may also play a role in the mentioned differences in the results. As in many cultures, adult males in the Turkish culture are expected to be circumcised. In Turkish society, circumcision may not lead to traumatic effects because the operation is performed in combination with various encouraging rituals and gifts given to the child circumcised. Supporting this assumption, $58 \%$ of the children mentioned at the previous study reported that they thought the circumcision is a necessary procedure to be a man. ${ }^{20}$ Additionally, another study performed in Turkey, supporting our findings, reported that fear levels of the children had diminished 10 days after the procedure and children older than 6 years old reported less fear than those younger than 6 years ${ }^{21}$. Also, children who had been undergone a circumcision procedure for religious reasons reported lower fear levels than for medical reasons. ${ }^{21}$ In light of these findings, it may be suggested that, in Turkey, circumcision supported by cultural rituals counterbalance any traumatic effects on children. This knowledge has been 
supported by a study from Turkey stating that social effects could limit the negative effects of circumcision. ${ }^{22}$ Besides, children exposed to circumcision operation over 6 years may experience less fear and related situations when compared to those under 6 years old.

The PTSD rates of the children after circumcision operation has been reported to be very high $(70 \%)$ in a study conducted in Philippines. ${ }^{7}$ However, the circumcision procedure described in that study was different from the procedure of our study. In the mentioned study, the operation was conducted in a rural area in which the children are apart from their parents and seeing each other during the procedure. In addition, no celebration or encouraging activities are organized before or after the operation and no anesthesia is administered for the operation. Because that procedure could be more traumatic than the procedure in Turkey, the PTSD levels could have been higher than our study.

In our study, although few PTSD symptoms were observed in both GA and LA groups, PTSD symptoms were observed to be more severe in the GA group, compared to those in the LA group. That was unexpected and opposite to our hypothesis, given that those circumcised under LA witnessed the operation, which may be considered to lead to traumatic effects in children. However, according to the principles of the behavioral theory on the anxiety, exposing an individual to the condition that is the source of the fear for enough time decreases the amount of the fear. Conversely, the more individuals avoid exposure to the source of the fear, the more intense the fear becomes. ${ }^{23}$ Based on these findings, it is possible that exposure to the feared procedure may have prevented children from perceiving it as traumatic. In addition, various studies indicate that, the procedures performed under GA and their risks are reported to increase anxiety levels. ${ }^{24,25}$ For this reason, these procedures may be found to lead to traumatic effects in children undergoing circumcision.

According to the study procedure, the decision on whether to use GA or LA was left up to the parents and children. So, it may be suggested that a bias was formed; children with anxiety may have chosen GA at a higher rate, and therefore the PTSD symptoms observed after circumcision would be more severe due to the children's existing anxiety. In the preoperative assessment period, however, it was observed that the children who were planning to be circumcised under LA actually had higher state anxiety levels, while the trait anxiety levels were the same. The role played by parents was also crucial in determining the type of anesthesia used. However, parents' anxiety and depression levels were not determined in the present study, which may be seen as one of its limitations. Also, the differences between socio-demographical features -including family income and education levels of parents of the two groups can be assumed as another limitation of this study. The socio-economic levels of the families in the LA group seems to be higher than the families of the GA groups. This could have affected the anesthesia method chosen for the procedure. These limitations should be held in mind while interpreting the findings of the present study.

The preoperative depression levels measured in children circumcised under LA, and the depression, as well as the state and trait anxiety levels of children circumcised under GA were found to correlate with the postoperative PTSD levels. However, when the effects of other variables were evaluated through regression analysis, we found that only being in the LA group and depression levels of the children before the operation predicted the PTSD symptoms after the operation. This finding is consistent with those of previous studies. Anxiety and depression levels have also been reported in many studies as important risk factors for the development of PTSD 26,27 . However, the regression analysis of our study revealed that depression is more important to predict PTSD symptoms rather than the anxiety symptoms. Thus, we can say that children with higher depression levels are more likely to develop PTSD symptoms due to exposure to circumcision. By determining the depression levels within the preoperative period, children scheduled for circumcision surgery can be monitored closely in terms of the development of PTSD symptoms. In some previous studies, the probability of developing PTSD symptoms by the children exposed to traumatic events is reported to be associated with their vulnerability to anxiety sensitivity. ${ }^{28,29}$ In contrast to those findings, 
no association was found between the anxiety sensitivity levels and PTSD symptoms in our study. The fact that the PTSD scores of the children were low -meaning the children did not perceive the circumcision operations performed in our study as serious traumas- may account for this difference.

Our study was conducted under some limitations. Among these limitations were the small size of sampling, data collection based on self-reported scales -collected only from children-, and the lack of diagnoses through structured interviews. Also, not measuring the psychiatric symptoms of parents may be regarded as another limitation. Additionally, most studies report that the anxiety and worry levels of the surgical procedures are related to the pain the patient experiences. We have not evaluated the pain levels of the children during or after the procedure. This is another limitation of the present study. Finally, no randomization was conducted in the selection of the groups in the present study.

The number of studies investigating the effects of circumcision on children's psychological health status seems to be quite limited. In our study, we found that circumcision operations did not lead to severe PTSD symptoms in children, circumcisions performed under GA had more negative effects on children in terms of PTSD symptoms than those performed under LA, and depression levels predicted PTSD symptoms. We consider that further studies, including larger sample sizes, investigating the possible effects of elective circumcision operations on children's psychological health should be performed.

\section{REFERENCES}

1. Wiswell TE. Circumcision circumspection. N Engl J Med 1997; 336: 1244-1245.

2. World Health Organization. Male Circumcision: Global Trends and Determinants of Prevalence, Safety, and Acceptability. Geneva, Switzerland: World Health Organization, 2007

3. Verma (Chairman) R, Alladi R, Jackson I, et al; Association of Anaesthetists of Great Britain and Ireland; British Association of Day Surgery. Day case and short stay surgery: 2. Anaesthesia 2011; 66: 417434.

4. Paix BR, Peterson SE. Circumcision of neonates and children without appropriate anaesthesia is unacceptable practice. Anaesth Intensive Care 2012; 40: 511-516.
5. Serour F, Cohen A, Mandelberg A, Mori J, Ezra S. Dorsal penile nerve block in children undergoing circumcision in a day-care surgery. Can J Anaesth 1996; 43: 954-958.

6. Cansever G. Psychological effects of circumcision. Br J Med Psychol 1965; 38: 321-331.

7. Ramos S, Boyle GJ. Ritual and medical circumcision among Filipino boys: Evidence of post-traumatic stress disorder. Eds: Denniston GC, Hodges FM, Milos MF. Understanding Circumcision: A Multi-Disciplinary Approach to a Multi-Dimensional Problem. New York, Plenum, 2001.

8. American Psychiatric Association. Diagnostic and Statistical Manual of Mental Disorders. Washington, DC: American Psychological Association Press, 1994

9. American Psychiatric Association. Diagnostic and Statistical Manual of Mental Disorders. Washington, DC: American Psychiatric Association, 2013.

10. Jordan GH, Schlossberg SM, Devine C. Surgery of the penis and urethra. Campbell-Walsh Urology. 9th ed. Philadelphia, Pa: Saunders, Elsevier, 2007.

11. Kovacs M. Rating scales to assess depression in schoolaged children. Acta Paedopsychiatr 1981; 46: 305-315.

12. Öy B. Çocuklar için depresyon ölçeği: Geçerlik ve güvenirlik çalışması. Türk Psikiyatri Dergisi 1991; 2: 132-136.

13. Spielberger CD. The measurement of state and trait anxiety: Conceptual and methodological issues. In: Levi L (ed). Emotions: Their parameters and measurement. New York, NY: Raven. 1975: 713-725.

14. Özusta HŞ. Çocuklar için durumluk-sürekli kayg envanteri uyarlama, geçerlik ve güvenirlik çalışması. Türk Psikoloji Dergisi 1995; 10: 32-44.

15. Silverman WK, Fleisig W, Rabian B, Peterson RA Childhood anxiety sensitivity index. J Clin Child Adolesc Psychol 1991; 20: 162-168.

16. Yılmaz S, Kılıç EZ. Cocuklar için anksiyete duyarlılı̆̆ indeksinin türkçe formunun geçerlik ve güvenirlik çalışması. Türk Psikiyatri Dergisi 2015; 26: 197-203.

17. Pynoos RS, Frederick C, Nader K, et al. Life threat and posttraumatic stress in school-age children. Arch Gen Psychiatry 1987; 44: 1057-1063.

18. Erden G, Kılıç EZ, Uslu R, Kerimoğlu E. The validity and reliability study of Turkish version of child posttraumatic stress reaction index. Turk J Child Adolesc Ment Health 1999; 6: 143-149.

19. Freud S. The origins of psycho-analysis: Letters to Wilhelm Fliess, drafts and notes. New York: Basic Books, 1954: 1887-1902.

20. Corduk N, Unlu G, Sarioglu-Buke A, Buber A, Savran B Zencir M. Knowledge, attitude and behaviour of boys and parents about circumcision. Acta Paediatr 2013; 102: e169-e173.

21. Sancar S, Demirci H, Guzelsoy M, et al. Fear of circumcision in boys considerably vanishes within ten days of procedure. Urol J 2016; 13: 2541-2545.

22. Yavuz M, Demir T, Doğangün B. The effect of circumcision on the mental health of children: A review. Turk Psikiyatri Derg 2012; 23: 63-70. 
23. Ohman A, Mineka S. Fears, phobias, and preparedness: Toward an evolved module of fear and fear learning. Psychol Rev 2001; 108: 483-522.

24. Mitchell M. General anaesthesia and day case patient anxiety. J Adv Nurs 2010; 66: 1059-1071.

25. Fekrat F, Şahin A, Yazıcı KM, Aypar Ü. Anaesthetists' and surgeons' estimation of preoperative anxiety by patients submitted for elective surgery in a university hospital. Eur J Anaesthesiol 2016; 23: 227-233.

26. Breslau N, Davis GC, Andreski P, Peterson E. Traumatic events and posttraumatic stress disorder in an urban population of young adults. Arch Gen Psychiatry 1991; 48: $216-222$.
27. Shalev AY, Peri T, Canetti L, Schreiber S. Predictors of PTSD in injured trauma survivors: A prospective study. Am J Psychiatry 1996; 153: 219-225.

28. Kılıç EZ, Kılıç C, Yılmaz S. Is anxiety sensitivity a predictor of PTSD in children and adolescents? J Psychosom Res 2008; 65: 81-86.

29. Boffa JW, Norr AM, Raines AM, Albanese BJ, Short NA, Schmidt NB. Anxiety sensitivity prospectively predicts posttraumatic stress symptoms following a campus shooting. Behav Ther 2016; 47: 367-376. 